\title{
Role of P.O visit, Ligature material examination and case history in Autopsy examination of hanging cases
}

\author{
Vibhakar Kumar, ${ }^{1, *}$, Rani Kumari Beck² \\ ${ }^{\mathbf{1}}$ Assistant Professor, ${ }^{2}$ Tutor, Dept. of FMT, MGM Medical College, Jamshedpur, Jharkhand
}

*Corresponding Author:

Email: vibhakar2000@gmail.com

\begin{abstract}
Hanging is a common mode of unnatural death in our society. A child aged 12 yrs to a person aged 89 years committed suicide by Hanging. Ligature marks over neck depends on various factors, like ligature material, type of hanging, duration of hanging, mental status of person at that time, hairs, beard, types of knot, number of turns of ligature and body wt. In some cases of hanging when the body released from ligature within minute after suspension then ligature mark may be not visible/faint/only knot marks visible over neck. In cases of partial hanging the ligature mark may present over mid neck placed transversely and mimics like strangulation. In such cases it is very difficult for autopsy Surgeon to decide whether it is a case of Hanging or Strangulation. If hanging then whether Suicidal/ Homicidal/ Accidental. To rule out the possibilities, P.O visit, ligature material examination and case history is very important.
\end{abstract}

\section{Introduction}

Hanging is a form of death, produced by suspending the body with a ligature round the neck, the constricting force being the weight of the body or the weight of the head alone. According to suspension of body it may be complete and partial. According to position of knot it may be typical or atypical.

The findings in cases of Hanging: Face usually pale, stretched neck, dribbling of saliva out of the mouth down on the chin and chest. Ligature mark found oblique non- continuous placed high up in the neck between the chin and the larynx, the base of the groove or furrow being hard yellow and parchment-like. Subcutaneous tissue are white hard and glistening. (Abrasions echymoses around the edges of ligature mark, injury of neck muscles, fracture of larynx and trachea and cervical vertebrae are rare).

Death in cases of hanging occur as a result of combined effect of asphyxia with apoplexy (commonest).Asphyxia alone; Apoplexy alone; Cerebral ischemia; Vagal shock and fracture and dislocation of $2^{\text {nd }}$ and $3^{\text {rd }}$ cervical vertebrae.

Medico legal aspect of hanging is whether it is Suicidal; Homicidal; Accidental or Post- mortem. Among these Suicidal is the commonest.

\section{Case History}

A dead body of 35 year old engineer male brought for autopsy from Sonari PS, East singhbhum with history of asphyxial death resulting from ligature material round the neck. The Person was resident of Bangalore resides here in a flat as a bachelor. His family along with parents resides at Bangalore. The body was found naked. The ligature mark present over middle of neck placed al around neck and is $37 \mathrm{cmX} 3 \mathrm{~cm}$ in size with abrasion, contusion, grooved and parchmentised.On dissection of neck the underneath tissue found contused at places over anterior aspect. Conjunctiva ecchymosed, lips and nails are cyanosed with seminal and fecal discharge. The condition of the body and findings go towards strangulation by ligature material. So to rule out I decide to visit the place of occurrence with IO. From where a mobile is recovered in switch off condition over a chair which indicates about recording of the events. After charging the mobile we examine it; surprisingly the whole events of hanging and death were recorded. The person first hang the bed sheet in sealing fan hook, remove the clothing's from body and go for recording of hanging (partial). First he put the loop behind middle of neck pass it anteriorly and starts to turn round and round for force of constriction. Both hands were placed over front of neck to hold the ligature at middle of neck. After few minutes the person start convulsion and then body goes in primary relaxation after death.

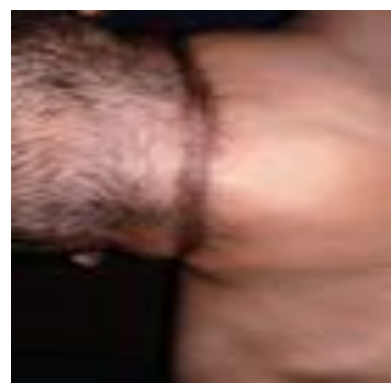

Ligature mark over mid portion of neck: A dead body of $32 \mathrm{yr}$ old unemployed unmarried male was brought for autopsy by birsanagar P.S East Singhbhum with history of asphyxial death resulting from ligature all-round mid neck. Ligature mark is two in no anterolateraly and one in number posteriorly. It is $48 \mathrm{~cm}$ in length and $0.8 \mathrm{~cm}$ in width. It is prominent all-round with abrasion, grooving and pachmentisation. On dissection of neck underneath tissues are pale and

IP International Journal of Forensic Medicine and Toxicological Sciences, July-September, 2017:2(2):42-43 42 
glistening. Abrasion of $1 \mathrm{cmX} 1 \mathrm{~cm}$ present over both knee front. Abrasion of $1 \mathrm{~cm} \mathrm{X} 0.6 \mathrm{~cm}$ over bridge of nose. Scalp of frontal region contused in $3 \mathrm{~cm} \mathrm{X} 2 \mathrm{~cm}$. This case also simulate like strangulation by ligature material. To rule out I took the history from brother who sees the body first. The history is person hang himself by a rope used for sundry of clothing's. The rope was tied with long iron rod of pillar. I visit the P.O and find that the both rod were bended forward and medially with cut plastic rope tied with rod ends. Plastic rope width and pattern corresponds with the ligature mark over neck.

A dead body of $28 \mathrm{yr}$ old married women brought for autopsy examination with history of fall from stairs. There were no any external and internal injuries except an abrasion of size $4 \mathrm{~cm} \mathrm{X} 1 \mathrm{~cm}$ over under surface of left chin. Internal organs are congested with little froth in lumen of trachea. There is no any evidence of ingested poisoning. On the basis of findings I simply ask the father that who released the ligature from neck of suspended body. Then he accepts that his son released the body from suspension and rush to hospital where she declared dead.

A dead body of male aged 29 years brought in hospital emergency at $2 \mathrm{~A}$ : M with history of Hanging for confirmation of death. My self declare dead after examination of diseased. On next day, dead body brought for autopsy examination in my department; with history of fall and presence of dark line over neck. I was surprised to see the history mentioned in Inquest given by family members. Of course autopsy surgeon gives asphyxia as a cause of death due to hanging.

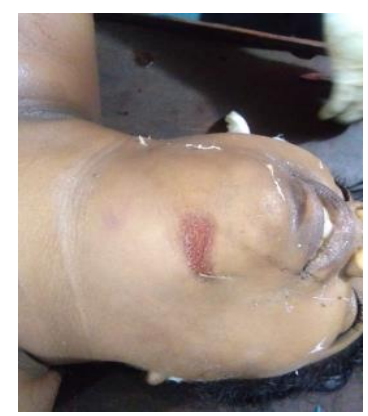

Knot marks in form of abrasion

In some cases of hanging in addition to ligature mark around the neck; internal head injuries are present. In such cases hanging may be suicidal or homicidal or post-mortem in nature. To rule out we must go through examination of ligature material and P.O visit.

\section{Discussion}

"Death" the word itself is enough to frighten a person, still worse, death by any act of violence is by far the most distressing of scenario, a person has to face, as Adelson in 1961 has very aptly stated-"there is one way to be born, but there are many way to die". An efficient death investigation process is essential for a truly caring community.

The first recorded hanging was that Daniell frank in Virginia on March 1, 1622 for cattle stealing. The earliest recorded female hanging was that of Jane Champion in 1632 in Virginia for an unknown offense.Hanging is most frequently observed since it is often chosen as a method of suicide As the Ligature marks over neck depends on various factors, like ligature material, type of hanging, duration of hanging, mental status of person at that time, hairs, beard, types of knot, number of turns of ligature and body wt. Ligature mark may be not visible/faint/only knot mark present/prominent all-around/prominent opposite to knot position. Other features and confirmatory sign of ante-mortem hanging (salivary stain) may present or not in all cases. So whenever there is any confusion then we must go for P.O visit, ligature material examination and case history. It will certainly confirm about the cause of death and nature of death.

\section{References}

1. Modi's Medical jurisprudence and Toxicology $23^{\text {rd }}$ edition;546-598.

2. Principles of Forensic Medicine including Toxicology Apurba Nandy Third ed 517-539.

3. The Essentials of Forensic Medicine and Toxicology. Dr. K.S. Narayan Reddy $31^{\text {st }}$ edition $314-339$.

4. Parikh's Textbook of Medical Jurisprudence Forensic Medicine and Toxicology. Sixth edition 3.40-3.60.

5. Review of Forensic Medicine and Toxicology including clinical and pathological aspests-. Gautam Biswas. $3^{\text {rd }}$ edition60-176

6. Forensic Medicine and Toxicology for MBBS -Anil Aggrawal $1^{\text {st }}$ edition-264-292.

7. Concise Text book of Forensic medicine and Toxicology $-\mathrm{R}$ K Sharma $1^{\text {st }}$ published -50-55.

8. Fundamentals of Forensic medicine and Toxicology $-2^{\text {nd }}$ - edition-227-247.

9. Textbook of Forensic Medicine (Medical jurisprudence and Toxicology)- Ajay kumar-131-142.

10. William Emoehazy. J. Emedicine Hanging injuries and strangulation, page-2.

11. Encyclopedia of forensic medicine and legal medicine $1^{\text {st }}$ edition. 